\title{
CAN THE LOTTERY PARADOX BE SOLVED BY IDENTIFYING EPISTEMIC JUSTIFICATION WITH EPISTEMIC PERMISSIBILITY?
}

\author{
BENJAMIN KIESEWETTER
}

benjamin.kiesewetter[at]hu-berlin.de

\begin{abstract}
Thomas Kroedel argues that the lottery paradox can be solved by identifying epistemic justification with epistemic permissibility rather than epistemic obligation. According to his permissibility solution, we are permitted to believe of each lottery ticket that it will lose, but since permissions do not agglomerate, it does not follow that we are permitted to have all of these beliefs together, and therefore it also does not follow that we are permitted to believe that all tickets will lose. I present two objections to this solution. First, even if justification itself amounts to no more than epistemic permissibility, the lottery paradox recurs at the level of doxastic obligations unless one adopts an extremely permissive view about suspension of belief that is in tension with our practice of doxastic criticism. Second, even if there are no obligations to believe lottery propositions, the permissibility solution fails because epistemic permissions typically agglomerate, and the lottery case provides no exception to this rule.
\end{abstract}

\section{THE LOTTERY PARADOX AND THE PERMISSIBILITY SOLUTION}

Thomas Kroedel has recently argued for a novel solution to Henry E. Kyburg's famous lottery paradox. ${ }^{\mathrm{I}}$ On a common construal, the paradox occurs if we apply two plausible assumptions about epistemic justification to the case of an agent A who knows that he is confronted with a fair lottery with a large number of tickets, one and only one of which will win. The first assumption is that we have justification to believe what is very likely, given our evidence:

The probability claim: If A's evidence makes p exceedingly likely, then A has justification for believing . $^{2}$

I Kyburg (I96I: I97), Kroedel (20I2). Recent discussions of Kroedel's permissibility solution include Littlejohn (20I2, 20I3), Huber (20I4), Eder (20I5), as well as Kroedel (20I3a, 20I3b, 20I7). Neither of these contributions addresses the objections that I raise in this paper.

2 Three clarificatory remarks on the relevant notions of 'justification' and 'belief': First, like Kroedel, I am primarily concerned with epistemic justification. Except when I explicitly address other possible forms of justification for doxastic states, I use 'justification' as short for 'epistemic justification'. Second, like Kroedel, I am concerned with what is sometimes called 'propositional justification' (in contrast to 'doxastic justification' which is concerned with the epistemic status of a particular belief token). Throughout 
Let us call a proposition of the form 'lottery ticket number $x$ will lose' a lottery proposition. Depending on the number of tickets involved in the lottery, the probability claim entails that for each lottery proposition, A has justification to believe it. By varying the number of tickets, we can generate this result for any degree of probability that we deem sufficient for justification, as long as it is below I.

The second assumption is that we have justification for believing a proposition if that proposition is a conjunction of two other propositions each of which we have justification to believe:

The conjunction claim: If A has justification for believing $\mathrm{p}$, and A has justification for believing $\mathrm{q}$, then A has justification for believing p\&q. ${ }^{3}$

The well-known problem is that these two initially plausible assumptions together entail the paradoxical conclusion that A has justification for believing that all lottery tickets will lose. To see this, let 'J' be the operator for justification, let 'B' be the operator for belief, let ' $\mathrm{l}_{\mathrm{x}}$ ' be the proposition 'lottery ticket number $x$ will lose', and let ' $\mathrm{n}$ ' be the number of tickets that the lottery contains. The argument can then be represented as follows:

(I) $\mathrm{JBl}_{\mathrm{I}} \& \ldots \& \mathrm{JBl}_{\mathrm{n}}$

(2) $(\mathrm{JBp} \& \mathrm{JBq}) \rightarrow \mathrm{JB}(\mathrm{p} \& \mathrm{q})$

(3) $\mathrm{JB}\left(\mathrm{l}_{\mathrm{r}} \& \ldots \& \mathrm{l}_{\mathrm{n}}\right)$

(I) states that for each lottery ticket, A has justification to believe that this ticket will lose, which is entailed by the probability claim. Through iterated applications of the conjunction claim (2), we reach the conclusion (3) that A has justification to believe that all tickets will lose. This conclusion is clearly false: we assumed that A knows that at least one ticket will win; A thus cannot have justification for believing that all tickets will lose. Kyburg concluded from this that justification is not as closely related to logic as it might have seemed and rejected the conjunction claim (2).4 While some epistemologists have followed him, others again resisted this conclusion and rejected the probability claim instead, thereby escaping the paradox by denying $(\mathrm{I}) .{ }^{5}$

this paper, I use 'A can justifiably believe p' and 'A has justification for believing p' equivalently in order to refer to this kind of justification, where 'having justification' in this paper always means having suffcient justification, not merely having partial justification. Third, again like Kroedel, I am concerned only with beliefs simpliciter, not with the quantitative notion of belief that allows for degrees. The lottery paradox is often discussed in the context of what Foley (I992: III) has dubbed the 'Lockean Thesis', according to which the standards of justification for belief simpliciter can be derived from the standards of justification for the degree of confidence that amounts to belief simpliciter. Despite what is sometimes asserted, however, the Lockean Thesis is not an essential premise of the lottery paradox, but only one possible motivation for the probability claim. It is perfectly consistent to deny the assumption (entailed by the Lockean Thesis) that the ordinary notion of belief simpliciter can be explained in terms of a quantitative notion of belief - as, for example, Skorupski (20IO: 5I) does while maintaining the probability claim with respect to belief simpliciter.

3 The conjunction claim also follows from the more general closure principle, according to which we have justification for believing a proposition if it logically follows from other propositions each of which we have justification to believe. I shall focus on the conjunction claim, however, since no stronger claim is needed to generate the paradox.

4 See also Kyburg (1970). 
How does Kroedel's permissibility solution relate to this dialectic? Although his own presentation of the paradox conceals this fact, Kroedel actually sides with Kyburg in giving up the conjunction claim, as it is usually understood. In contrast to Kyburg, however, Kroedel thinks that there is an alternative interpretation of the conjunction claim that can be maintained in the light of the lottery paradox even if we hold on to the probability claim. According to this alternative interpretation, the justification operator in the antecedent of the conjunction claim takes wide scope over 'believing $\mathrm{p}$ and believing q':

The wide-scope conjunction claim: If A has justification for believing $\mathrm{p}$ and believing $\mathrm{q}$, then $\mathrm{A}$ has justification for believing p\&q. $[\mathrm{J}(\mathrm{Bp} \& \mathrm{~Bq}) \rightarrow J B(\mathrm{p} \& \mathrm{q})]$

If we replace (2) with this wide-scope version of the conjunction claim, the paradoxical conclusion (3) does not follow anymore. This solution requires, however, that the following principle is false:

Justification agglomeration: If A has justification for believing $\mathrm{p}$, and A has justification for believing $\mathrm{q}$, then A has justification for believing $\mathrm{p}$ and believing $\mathrm{q} .[(\mathrm{JBp} \& \mathrm{JBq}) \rightarrow \mathrm{J}(\mathrm{Bp} \& \mathrm{~Bq})]$

This is because the permissibility solution is supposed to preserve the probability claim and its implication that for each lottery proposition, A has justification to believe it (I). If justification agglomerates, however, it follows from (I) that A has justification for having all lottery beliefs together and we can run the following argument to the paradoxical conclusion:

(I) $)_{\mathrm{WS}} \mathrm{J}\left(\mathrm{Bl}_{\mathrm{I}} \& \ldots \& \mathrm{Bl}_{\mathrm{n}}\right)$, from (I) by justification agglomeration

(2) $\mathrm{Ws} \mathrm{J}(\mathrm{Bp} \& \mathrm{~Bq}) \rightarrow \mathrm{JB}(\mathrm{p} \& \mathrm{q})$, wide-scope conjunction claim

(3) $\mathrm{JB}\left(\mathrm{l}_{\mathrm{I}} \& \ldots \& \mathrm{l}_{\mathrm{n}}\right)$

Kroedel's attempt to rescue a version of the conjunction claim while holding on to the probability claim thus depends essentially on his rejection of justification agglomeration. His argument is that since 'justification is a species of permissibility', ${ }^{6}$ and 'permissibility does not agglomerate', 7 justification likewise fails to agglomerate. If it works, his solution would be a significant achievement, since we could maintain the intuitive connection between justification and probability while holding on to at least a version of the conjunction claim. ${ }^{8}$

5 See e.g. Foley (I979) and Klein (1985) for the rejection of the conjunction claim, and Ryan (I996) and Nelkin (2000) for the rejection of the probability claim.

6 Kroedel (201 2: 57). Note that Kroedel does not actually explicitly endorse the claim that justification is a species of permissibility; strictly speaking, he argues only for the conditional claim that if justification is a species of permissibility, then this provides a solution to the lottery paradox.

7 Kroedel (2012: 59).

8 Kroedel's presentation of both the paradox and his solution differs from mine in some respects. In his original article (Kroedel 2OI2), he does not even mention what I take to be the standard interpretation of the conjunction claim (2), but simply assumes the wide-scope version (2) Ws as the relevant claim at issue. Disregarding (2), he then argues that the paradoxical conclusion follows only if the first premise is interpreted as the wide-scope claim (I) WS rather than the narrow-scope claim (I). Kroedel thus seems to take the lottery paradox to consist in the fact that $(\mathrm{I})_{\mathrm{WS}}$ and $(2)_{\mathrm{WS}}$ entail $(3)$, and his solution to consist 
In this article, I present and discuss two objections to the permissibility solution. The first objection grants Kroedel's assumption that justification by itself amounts to no more than an epistemic permission, but argues that it is nonetheless plausible to assume that there are obligations to believe highly probable propositions under certain conditions that a lottery case might satisfy. It follows that the lottery paradox recurs at the level of such obligations $(\mathbb{2} 2)$. The second objection is that the permissibility solution fails even if there are no obligations to believe lottery propositions, because it requires that justification fails to agglomerate in the lottery case. I argue that a qualified version of justification agglomeration is plausible even if justification amounts to no more than epistemic permissibility, and that denying agglomeration in the lottery case creates a dilemma $\left(\mathbb{S}_{3}\right)$.

\section{FIRST OBJECTION: OBLIGATIONS TO BELIEVE LOTTERY PROPOSITIONS}

As we have seen, the permissibility solution to the lottery paradox is based on the assumption that a person's having justification for a belief is to be identified not with this person's being obligated or required, but with this person's being permitted to have this belief. ${ }^{9}$ This is a tenable view, and I shall grant it for the sake of the argument. As Gilbert Harman in particular has emphasized, there is no point in cluttering one's mind with an abundance of trivial or otherwise uninteresting beliefs, even if we could justifiably have them. ${ }^{\text {Io }}$ And as Mark Nelson has argued, a duty to believe every proposition that our evidence justifies would amount to a duty that we could not possibly satisfy, since our evidence always justifies an infinite number of possible beliefs. ${ }^{\text {II }}$ Plausibly, then, we are not obligated to believe everything we are in a position to believe justifiably.

However, the truth of this claim does not suffice for the permissibility solution to succeed. That justification does not necessarily amount to epistemic obligation does not entail that justification does not give rise to epistemic obligation under certain conditions that a lottery case might satisfy. And if there are such conditions under which justification gives rise to epistemic obligation, then the lottery paradox can be restated in terms of such obligations, no matter whether justification as such amounts to permissibility or obligation.

\section{I Bridge principles and the permissibility solution}

To illustrate this worry with the permissibility solution, consider:

Bridge pattern: A ought to believe p iff (i) A has justification for believing $\mathrm{p}$, and (ii) condition C obtains.

in substituting (I) for (I) Ws. In my view, he thereby overlooks the central paradox, which consists in the fact that (I) and (2) entail (3). In a later discussion (Kroedel 20I3 a: $\$ 2$ ), he acknowledges this version of the paradox and explicitly states that he rejects not only (I) WS but also (2). Ultimately, these are matters of presentation only. Whether the central paradox is that (3) is entailed by (I) and (2) or that it is entailed by (I) Ws and (2) Ws, in either case Kroedel accepts both (I) and (2) Ws, while rejecting both (I)WS and (2), and in either case this commits him to denying justification agglomeration.

9 In this article, I use the terms 'obligation', 'requirement' and 'duty' interchangeably in order to refer to the epistemic 'ought'. No moral connotations are intended by the use of any of these terms.

Io See Harman (I986: I2-I5).

I I See Nelson (2010: esp. 96-8). Whiting (2012: 292) also makes this point. 
Different views about how condition C needs to be understood for Bridge pattern to come out as true are possible. Drawing on Gilbert Harman, we may say that $\mathrm{C}$ is the condition that $\mathrm{A}$ is interested in whether $\mathrm{p}$ is the case. ${ }^{\mathrm{I} 2}$ Drawing on Robert Nozick, we may say that $\mathrm{C}$ is the condition that A's expected utility of believing $\mathrm{p}$ is higher (or at least not lower) than the expected utility of having no belief about whether $\mathrm{p}$ is the case. ${ }^{\mathrm{I} 3} \mathrm{My}$ own view is that $\mathrm{C}$ is the condition that $\mathrm{A}$ pays sufficient attention to the question of whether $\mathrm{p}$ is the case. $^{\mathrm{I}} 4$ But my aim here is not to defend a particular view about condition C. I mention these different accounts only to illustrate that there are various ways to avoid the implausible implications of a view that identifies justification with epistemic obligation while still holding on to the intuitively plausible claim that we are sometimes required, and not merely permitted, to have epistemically justified beliefs.

Before I will say a bit more in defence of this claim, let me briefly explain the problem that it poses for the permissibility solution. Suppose that one of the mentioned views about condition $\mathrm{C}$ is correct. We may then stipulate a lottery case in which condition $\mathrm{C}$ is satisfied for every lottery proposition. Imagine, for example, that A considers buying a lottery ticket and can choose any particular ticket. For each ticket, she is interested in the question whether the ticket will lose, she explicitly asks herself of every lottery proposition whether it is true, and for each lottery proposition that she considers, it is indeed the case that the expected utility of believing it is higher than the expected utility of suspending judgement. Our bridge principle will then entail, together with the probability claim, that for each lottery proposition, A ought to believe it. ${ }^{\mathrm{I} 5}$ And since obligations agglomerate (as the proponent of the permissibility solution agrees), and epistemic obligations imply epistemic justification, we will not be able to avoid the paradoxical conclusion that $\mathrm{A}$ has justification to believe that all tickets will lose unless we give up the conjunction claim in the wide-scope reading that the permissibility solution aims to preserve as well. Taking ' $\mathrm{O}$ ' as the operator for epistemic obligation, this argument can be represented as follows:

(4) $\mathrm{OBl}_{\mathrm{I}} \& \ldots \& \mathrm{OBl}_{\mathrm{n}}$

(5) $\mathrm{O}\left(\mathrm{Bl}_{\mathrm{I}} \& \ldots \& \mathrm{Bl}_{\mathrm{n}}\right)$, from 4 by obligation agglomeration $[(\mathrm{OBp} \& \mathrm{OBq}) \rightarrow \mathrm{O}(\mathrm{Bp} \& \mathrm{~Bq})]$

(6) $\mathrm{J}\left(\mathrm{Bl}_{\mathrm{I}} \& \ldots \& \mathrm{Bl}_{\mathrm{n}}\right)$, from 5 by obligation implies justification $[\mathrm{O}(\mathrm{Bp}) \rightarrow \mathrm{J}(\mathrm{Bp})]$

(7) $\mathrm{JB}\left(1_{\mathrm{I}} \& \ldots \& \mathrm{l}_{\mathrm{n}}\right)$, from 6 by wide-scope conjunction claim $[\mathrm{J}(\mathrm{Bp} \& \mathrm{~Bq}) \rightarrow \mathrm{JB}(\mathrm{p} \& \mathrm{q})]$

I2 Cf. Harman (I986: 55 ).

I3 Cf. Nozick (I993: 86).

I 4 See Kiesewetter (20I7: I 80-5). One argument in favour of this latter view is that it makes good sense of how the assumption that sufficient evidence for $\mathrm{p}$ is not by itself enough to ground an obligation to believe $\mathrm{p}$ fits together with Richard Moran's famous observation that the first-personal deliberative question of whether to believe $\mathrm{p}$ is transparent on the theoretical question of whether $\mathrm{p}$ is the case (cf. Moran I988: I43). My account of condition C explains this, because it entails that once one considers this question in deliberation, sufficient evidence for $\mathrm{p}$ does suffice for an obligation to believe $\mathrm{p}$.

I 5 It is no reply to say that since agents like us are psychologically incapable of attending to all lottery propositions at the same time, there is no time at which A is obligated to have each lottery belief. Apart from the fact that this reply presupposes an unnecessarily restrictive interpretation of the attention condition, it ignores that we may simply stipulate an agent who has this capacity, and that we still want to deny that such an agent has justification for believing that all tickets will lose. 
A proponent of the permissibility solution thus needs to reject any instance of the bridge pattern that, together with the probability claim, entails (4).

Kroedel is committed to the existence of epistemic obligations himself: the permissibility solution maintains that in a lottery case, we are not permitted to believe that all tickets will lose, which is equivalent to saying that we are obligated not to believe that all tickets will lose. ${ }^{\mathrm{I}}$ This, however, is a negative epistemic obligation, while the bridge pattern generates positive epistemic obligations. To escape the problem, Kroedel may thus want to follow Nelson (to whom he refers in a note), and others such as Daniel Whiting, in denying the existence of any positive epistemic obligations. ${ }^{17}$ Let's call this view epistemic permissivism.

\subsection{Epistemic permissivism}

Despite first appearances, however, epistemic permissivism does not actually support the permissibility solution. To see this, note that neither Nelson nor Whiting argue that there is no true instantiation of the bridge pattern. Rather, they argue that a true instantiation of the bridge pattern must mention non-epistemic considerations in $\mathrm{C}$, and that for this reason, obligations to believe are never really epistemic obligations. As Nelson puts it:

My thesis is that there is nothing we positively ought to believe simply in virtue of our epistemic circumstances, and nothing that we 'ought' to believe at all, except given some further interest, desire, duty, or such like. ${ }^{18}$

I disagree with Nelson on two points. For one, as should be clear from what I have said above, I do not think that condition $\mathrm{C}$ must involve a reference to non-epistemic conditions, and I do not think that Nelson's argument shows anything like that. Nelson argues that the quality of an agent's evidence alone never suffices for an obligation to believe, but it does not follow that such obligations must be conditional on 'some further interest, desire, duty, or such like'. The relevant condition may, for example, be that A pays attention to the relevant proposition, and this is arguably part of A's 'epistemic circumstances'. For another, even if Nelson is right to say that $\mathrm{C}$ must involve a non-epistemic condition, it seems to me that the obligations resulting from the bridge pattern may still legitimately be called epistemic obligations (or epistemic duties, or epistemic requirements) as long as those obligations are not in any way based on non-epistemic reasons for belief. Nelson does not claim that obligations to believe are based on non-epistemic reasons for belief, however. His view is rather that sufficient epistemic reasons lead to obligations only if practical background conditions are satisfied. It seems to me perfectly fine to call such obligations epistemic obligations nonetheless. By way of an analogy, it seems to me a perfectly intelligible and consistent view to maintain that there are prudential requirements to

I6 Kroedel is explicit about this; see Kroedel (2OI2: 58) for the first of these claims, and Kroedel (20I 3 a: Iо8) for the second.

I7 See Nelson (2010); Whiting (20I2: esp. \$5). In his original article (Kroedel 20I2), Kroedel does not claim that there are no epistemic obligations, but only that epistemic justification does not amount to epistemic obligation. In more recent work, however, Kroedel locates his permissibility solution within 'the broader project of understanding epistemic norms in terms of permissions' (Kroedel 20I7: 2), which suggests that he accepts epistemic permissivism. 
act in accordance with weighty prudential reasons, but only if certain moral background conditions are satisfied.

Most importantly, however, even if we accepted that obligations to have beliefs always have practical background conditions and that they are therefore never epistemic obligations, this still would not support the permissibility solution. For as long as we maintain that some instance of the bridge pattern provides obligations to believe - and neither Nelson nor Whiting deny this - the lottery paradox can be restated in terms of such doxastic obligations, no matter whether these are to be called epistemic obligations or not.

For example, suppose that we have some kind of non-epistemic obligation ' $\mathrm{O}$ *' to believe a proposition $\mathrm{p}$ iff we have epistemic justification to believe $\mathrm{p}$ and the truth of $\mathrm{p}$ matters to us. Next, suppose for the sake of the argument that the truth of each lottery proposition matters to us. We can then restate the lottery paradox in terms of such non-epistemic obligations:

(8) $\mathrm{O} * \mathrm{Bl}_{\mathrm{I}} \& \ldots \& \mathrm{O} * \mathrm{Bl}_{\mathrm{n}}$

(9) $\mathrm{O} *\left(\mathrm{Bl}_{\mathrm{I}} \& \ldots \& \mathrm{Bl}_{\mathrm{n}}\right)$, from 8 by obligation agglomeration

(го) $\mathrm{J}\left(\mathrm{Bl}_{\mathrm{I}} \& \ldots \& \mathrm{Bl}_{\mathrm{n}}\right)$, from 9 by obligation implies justification $[\mathrm{O} *(\mathrm{Bp}) \rightarrow \mathrm{J}(\mathrm{Bp})]$

( I I) $\mathrm{JB}\left(\mathrm{l}_{\mathrm{I}} \& \ldots \& \mathrm{l}_{\mathrm{n}}\right)$, from Io by wide-scope conjunction claim $[\mathrm{J}(\mathrm{Bp} \& \mathrm{~Bq}) \rightarrow \mathrm{JB}(\mathrm{p} \& \mathrm{q})]$

\subsection{Doxastic permissivism}

Proponents of the permissibility solution might try to resist this argument in either of two ways. In order to reject (8), they might either go further than the epistemic permissivists and deny that there are any positive doxastic requirements at all, at least when the probability of the relevant proposition is below $\mathrm{I}$ :

Doxastic permissivism: No matter how carefully we attend to the question of whether $\mathrm{p}$, and no matter how important that question is from a practical standpoint, as long as the probability of $\mathrm{p}$ is less than $\mathrm{I}$, we are always permitted (epistemically and otherwise) to refrain from believing $\mathrm{p}$.

Alternatively, they might accept that there are obligations to have beliefs, but deny that these obligations entail epistemic justification, and thus reject (Io). Although it is beyond the scope of this article to show that these options are ultimately untenable, it is safe to say that both are very controversial and face serious problems.

Doxastic permissivism seems at odds with our practice of doxastic criticism. We criticize persons not only for believing against their evidence, but at least sometimes also for not believing in accordance with their evidence. Such criticism presupposes that there are obligations, and not just permissions, to have beliefs. Just as blame in general involves the assumption that an agent has failed to conform to a requirement and not merely omitted to make use of a permission, blame or criticism of doxastic attitudes involves the assumption that the agent has failed to conform to a doxastic requirement, not merely omitted to make use of a doxastic permission. ${ }^{19}$

I9 Kroedel (2013a: I07-8) accepts that epistemic blameworthiness entails impermissibility and thus a violation of an epistemic obligation. For an argument to the more general conclusion that a person is criticizable for omitting to $\mathrm{F}$ only if she has decisive reasons, or ought all things considered, to $\mathrm{F}$, see Kiesewetter (2017: Ch. 2). 
Consider Smith and Jones, two climate scientists who are both tied to political organizations that deny climate change. Both have very strong evidence for climate change, even though there is a residual probability that the data are misleading. Both are interested in the question of whether climate change is happening and pay sufficient attention to it. While Smith believes that climate change is not happening, Jones suspends judgement on that question and does not form a belief about climate change at all. It seems to me that Smith and Jones are both rationally criticizable for their doxastic states. Jones does not escape such criticism merely by suspending judgment. ${ }^{20}$ This, however, can be so only if there are obligations not only to abstain from beliefs that are unlikely to be true, but also to have beliefs that are likely to be true (under certain conditions). ${ }^{2 \mathrm{I}}$

Note that epistemic permissivists like Nelson and Whiting can accommodate the fact that Jones' doxastic state is criticizable precisely because they do not accept doxastic permissivism. For example, Whiting holds that "there are cases in which we criticize subjects for not believing propositions for which they possess sufficient evidence" 22 , and he emphasizes that his view "can account for the fact that there are many cases in which, given other factors, we do think that a subject should ... believe a proposition given the evidence" ${ }^{23}$. Epistemic permissivists only maintain that the relevant obligation is not a purely epistemic one. But as the argument from (8)-(I I) shows, for the lottery paradox it is not relevant whether the doxastic obligation is purely epistemic or not, as long as we assume that it entails epistemic justification.

So could we salvage the permissibility solution by denying that the doxastic obligations that we presuppose when we criticize Jones entail epistemic justification? Prima facie at least, the phenomenon of doxastic criticism supports the entailment: it seems that Jones' criticizability is undermined if we assume that he lacks epistemic justification for believing in climate change, and the most natural explanation for this is that the relevant obligation is undermined in the same way. Nelson and Whiting also do not appeal to obligations to have unjustified beliefs; their epistemic permissivism is supposed to accommodate non-epistemic obligations to have justified beliefs, not to have unjustified beliefs. ${ }^{24}$

Moreover, there are powerful arguments for the view that there cannot be obligations to have unjustified beliefs. An obligation of this sort seems to presuppose the existence of non-epistemic reasons for belief, but it has been argued that the existence of such reasons is ruled out by plausible constraints on the notion of a normative reason, such as the constraint that a reason for belief must be capable of being a reason for which one believes, or

20 This also counts against Nozick's view. We may assume that Jones' expected utility of suspending judgement is higher than that of forming a belief about climate change, but he seems rationally criticizable for suspending judgement nonetheless.

2 I Some authors deny this on the assumption that one cannot justifiably believe $\mathrm{p}$ if one knows that one does not know p (cf. e.g. Littlejohn 20I2: 5I2). I take it, however, that the point I am making about doxastic criticism also counts against this restrictive assumption. In any case, the response is not available to the proponent of the permissibility solution, since it is an essential part of this solution to preserve the initially plausible assumption that for each of the tickets, one can justifiably believe that it will not win.

Whiting elsewhere argues for a constraint on reasons that rules out pragmatic reasons for belief (Way and Whiting 2016: see esp. 227). On the natural assumption that obligations to have unjustified beliefs presuppose the existence of such reasons, this means that he is committed to denying the existence of such obligations. 
capable of figuring as a premise of (good) reasoning or deliberation. ${ }^{25}$ Needless to say, not everyone has been convinced by these arguments, ${ }^{26}$ and a satisfactory discussion is beyond the scope of this article. Two points seem worth noting nevertheless. Firstly, a commitment to the existence of obligations to have unjustified beliefs is at least a significant and highly controversial commitment. Secondly, it would be quite surprising if the correct solution to the lottery paradox - a paradox about epistemic justification - would hinge on the existence of such obligations. So no matter what one thinks about obligations to have unjustified beliefs, it seems to speak against the permissibility solution that one needs to assume such obligations in order to avoid the charge of an extreme and implausible form of permissivism about beliefs. In any case, I shall disregard the possibility of such obligations in what follows.

\subsection{A consistency condition on doxastic obligations?}

On behalf of the permissibility solution, it might now be suggested that there may be an account of the relevant condition $\mathrm{C}$ of the bridge pattern that excludes obligations to believe lottery propositions, while at the same time allowing the existence of obligations to believe other epistemically justified propositions that are less than absolutely certain. ${ }^{27}$ It is unclear, however, whether an account of such a condition can be given without introducing extremely ad hoc assumptions about the content of propositions that we may be required to believe (such as, for example, the assumption that a belief can be required only if it is not about a lottery ticket). To see this, let us briefly consider some attempts to provide a condition that rules out lottery propositions on grounds of their relevant structural features. At first sight, it might seem that proponents of the permissibility solution could put forward a view according to which A has an obligation to believe a proposition $\mathrm{p}$ that she has justification to believe iff

CI A attends to $\mathrm{p}^{28}$ and $\mathrm{p}$ is consistent with the conjunction of all other propositions that A justifiably believes.

But unless we assume that A has already formed beliefs about lottery propositions (which is not essential for a lottery case), this does not rule out the assumption that proponents of the permissibility solution wish to avoid, namely that for each lottery proposition, A is obligated to believe it. Alternatively, it might be suggested that A has an obligation to believe a proposition $\mathrm{p}$ that she has justification to believe iff

C2 A attends to $\mathrm{p}$ and $\mathrm{p}$ is consistent with the conjunction of all other propositions that $\mathrm{A}$ has justification to believe.

25 For arguments along these lines, see e.g. Kelly (2002), Kolodny (2005: \$3), Parfit (20 I I: App. A), Shah (2006), Way (2016), Way and Whiting (2016).

26 See e.g. Rinard (2015). It is worth noting that Rinard's general view about the norms of belief cannot be employed on behalf of the permissibility solution, as I explain below in note $4 \mathrm{I}$.

27 These doxastic obligations might either be understood as epistemic obligations (contrary to epistemic permissivism), or as justification-entailing non-epistemic obligations (consistently with epistemic permissivism).

28 Some condition like this is still necessary to avoid Harman's and Nelson's points discussed above. The reader is free to replace this part with her favourite theory of how to account for these points. 
Yet since the permissibility solution is committed to the probability claim, and thus the assumption that for each lottery proposition, A has justification to believe it, and since A knows how many tickets are involved and that one of them will win, it follows that the conjunction of all propositions that A has justification to believe is already inconsistent. As a consequence, there cannot be a proposition that is consistent with this conjunction, and so $\mathrm{C}_{2}$ effectively rules out all positive doxastic obligations.

$\mathrm{C}_{2}$ might be relaxed by saying that $\mathrm{A}$ has an obligation to believe a proposition $\mathrm{p}$ that she has justification to believe iff

$\mathrm{C}_{3} \mathrm{~A}$ attends to $\mathrm{p}$ and $\mathrm{p}$ is consistent with each proposition $\mathrm{q}$ that $\mathrm{A}$ has justification to believe. ${ }^{29}$

But this condition seems too weak to exclude obligations to have lottery beliefs. Consider a particular lottery proposition $l_{x}$. In order for $C_{3}$ to exclude an obligation to believe $l_{x}$, there would need to be a proposition q such that in a lottery case, A has justification to believe $\mathrm{q}$, and $\mathrm{q}$ is inconsistent with $\mathrm{l}_{\mathrm{x}}$. But since $\mathrm{l}_{\mathrm{x}}$ is extremely likely, every proposition inconsistent with $1_{\mathrm{x}}$ is extremely unlikely. And so we should not assume that A has justification to believe it. To illustrate this point, an example that comes to mind for a proposition that is inconsistent with $l_{x}$ is the conjunction consisting of the proposition that one ticket will win and all lottery propositions but $l_{x}$. But since that conjunction is extremely unlikely, we should not assume that A has justification to believe it. The same will be true for every other proposition that is inconsistent with $\mathrm{l}_{\mathrm{x}}$. For this reason, $\mathrm{C}_{3}$ does not rule out an obligation to believe $1_{\mathrm{x}}$.

To escape this problem, it seems that proponents of the permissibility solution have to put forward a stronger condition, according to which A has an obligation to believe a proposition $\mathrm{p}$ that she has justification to believe iff

$\mathrm{C}_{4} \mathrm{~A}$ attends to $\mathrm{p}$ and $\mathrm{A}$ has justification to believe $\mathrm{p}$ in conjunction with each proposition $\mathrm{q}$ that $\mathrm{A}$ has justification to believe. ${ }^{30}$

This condition will indeed exclude requirements to believe lottery propositions. Since A lacks justification to believe the conjunction of all lottery propositions, there will be some conjunction of lottery propositions $1_{\mathrm{I}} \& \ldots \& \mathrm{l}_{\max }$, such that A lacks justification

29 Alternatively, one might also put forward $\mathrm{C}_{3}$ *: A attends to $\mathrm{p}$ and $\mathrm{p}$ is consistent with every conjunction of propositions $p_{I} \& \ldots \& p_{n}$ that is such that $A$ can justifiably have the belief-set $\left\{B\left(p_{I}\right), \ldots, B\right.$ $\left(\mathrm{p}_{\mathrm{n}}\right)$ \}. I do not discuss this condition separately because I take it that on Kroedel's view, $\mathrm{C}_{3}$ and $\mathrm{C}_{3}{ }^{*}$ are coextensional. The reason for this is that according to any plausible view, if A has justification for believing $\left(\mathrm{p}_{\mathrm{I}} \& \ldots \& \mathrm{p}_{\mathrm{n}}\right)$, then $\mathrm{A}$ has justification for having the belief-set $\left\{B\left(\mathrm{p}_{\mathrm{I}}\right), \ldots, \mathrm{B}\left(\mathrm{p}_{\mathrm{n}}\right)\right\}$. This claim, together with the wide-scope conjunction claim, entails the following set justification principle: A has justification for having the belief-set $\left\{B\left(p_{I}\right), \ldots, B\left(p_{n}\right)\right\}$ if, and only if, $A$ has justification for believing $\left(\mathrm{p}_{\mathrm{I}} \& \ldots \& \mathrm{p}_{\mathrm{n}}\right)$. And on the assumption of this principle, $\mathrm{C}_{3} *$ is satisfied if, and only if, $\mathrm{C}_{3}$ is satisfied.

30 Alternatively, one might also put forward $\mathrm{C}_{4}$ *: A attends to $\mathrm{p}$ and for every belief-set $\mathrm{S}$ that $\mathrm{A}$ can justifiably have, the set that results from adding the belief that $\mathrm{p}$ to $\mathrm{S}$ is one that $\mathrm{A}$ can also justifiably have. For the reasons mentioned in the preceding note, on Kroedel's view $\mathrm{C}_{4}$ * is satisfied if, and only if, $\mathrm{C}_{4}$ is satisfied. 
to believe the conjunction $l_{\mathrm{I}} \& \ldots \& 1_{\max +\mathrm{I}}$. And so $\mathrm{C}_{4}$ rules out obligations to believe lottery propositions.

The problem is that $\mathrm{C}_{4}$ rules out all other obligations to believe propositions that are less than absolutely certain as well. Think of a proposition q such that the probability $\mathrm{P}(\mathrm{q})$ is barely sufficient to render a belief in $\mathrm{q}$ justified - any further decrease of $\mathrm{P}(\mathrm{q})$ would mean that $\mathrm{q}$ is insufficiently likely for justification. Plausibly, for every proposition $\mathrm{p}$ that we have justification to believe, there will be a p-independent proposition $q$ that is barely sufficiently likely among the multitude of propositions that we have justification to believe (we can easily arrive at such a barely sufficiently likely proposition by conjoining other propositions that are more likely to a conjunction). Now suppose that the probability of $\mathrm{p}$ is below $\mathrm{I}$. Provided that $\mathrm{p}$ and $\mathrm{q}$ are independent, it follows that the probability $\mathrm{P}$ ( $\mathrm{p} \& \mathrm{q}$ ) is lower than the probability $\mathrm{P}(\mathrm{q})$ and thus insufficient for justification. Thus, on the reasonable assumption that among the propositions that we have justification to believe is one that is barely sufficiently likely, $\mathrm{C}_{4}$ rules out all requirements on beliefs that are less than absolutely certain.

The upshot of this discussion is that it is far from clear whether a condition can be found that rules out obligations to have lottery beliefs on grounds of considerations concerning their relevant structural features without ruling out all obligations to have beliefs that are less than absolutely certain. This should not surprise us. On the most general level, what generates the lottery paradox is the fact that the probability of a conjunction of two independent propositions that are less than absolutely certain is generally lower than the probability of the conjuncts. ${ }^{3 r}$ This is a general feature of propositions that are less than certain: when such propositions are conjoined in a conjunction, probability gets lost. If one wishes to avoid the implausible conclusion that one can have justification for believing highly unlikely conjunctions, then one either needs to reject obligations to have beliefs that are less than certain, or one needs to reject the claim that one always has justification to believe the conjunction of all propositions that one is individually obligated to believe. That latter claim is, as I have shown above, a commitment of anyone who accepts the wide-scope conjunction claim. ${ }^{32}$ It is also a commitment of anyone who accepts the narrow-scope conjunction claim. 33 And so anyone who wishes to preserve the conjunction claim (in either the narrow- or the wide-scope version) has to deny the existence of obligations to have beliefs that are less than absolutely certain.

\subsection{Summary}

Let me briefly sum up this section. That justification does not generally amount to epistemic obligation seems plausible, but it does not entail that there are no epistemic obligations if certain background conditions are satisfied. If there are such obligations, however, then the lottery paradox recurs on the assumption that the conditions in question are

3 I The same fact is also what generates the structurally very similar paradox of the preface, put forward by Makinson (1965).

32 For epistemic obligations, this is shown by the argument from (4) to (7). For non-epistemic obligations, this is shown by the argument from (8) to (II).

33 This is clear from the fact that since epistemic obligation entails epistemic justification, (4) entails (I), and given the narrow-scope conjunction claim (2), (I) entails (3). The same is true for non-epistemic obligations that entail epistemic justification: (8) entails (I), which together with (2) entails (3). 
satisfied, as is shown by the argument from (4) to (7). To avoid this problem, the proponent of the permissibility solution might adopt epistemic permissivism, which denies the existence of any positive epistemic obligations. However, epistemic permissivism allows for the existence of non-epistemic obligations to believe epistemically justified propositions if certain background conditions are satisfied and is indeed most plausible in combination with this assumption. As the argument from (8) to (I I) shows, the lottery paradox can be restated in terms of such non-epistemic obligations, unless one adopts the problematic and highly controversial view that we can be obligated to have unjustified beliefs. Setting this option aside, the permissibility solution requires a strong form of doxastic permissivism, which rules out the existence of any positive obligations to have justified beliefs that are less than absolutely certain. Although it is beyond the scope of this article to demonstrate that this view is ultimately untenable, I hope to have shown that our practice of doxastic criticism provides a serious challenge for it. In any case, it seems clearly a contentious commitment that is in need of further justification.

\section{SECOND OBJECTION: JUSTIFICATION AGGLOMERATES IN THE LOTTERY CASE}

I have argued that even if justification amounts to no more than epistemic permissibility, the lottery paradox re-emerges at the level of doxastic obligations unless one adopts an implausibly permissive view about suspension of belief. In this section, I shall argue that the permissibility solution fails even if we accept doxastic permissivism. This is because, as was demonstrated in the introduction, the permissibility solution requires that in the lottery case, the following principle fails to apply:

Justification agglomeration: If A has justification for believing $\mathrm{p}$, and A has justification for believing $\mathrm{q}$, then $\mathrm{A}$ has justification for believing $\mathrm{p}$ and believing $\mathrm{q}$.

I shall argue that no matter whether justification amounts to permissibility or obligation, justification agglomerates in the lottery case.

\section{I Preliminaries}

Let me begin with a logical point. Kroedel's argument against justification agglomeration is that justification is a species of permissibility and permissions do not agglomerate. Kroedel is right to say that permissions do not generally agglomerate. His example illustrates this point well: one may be permitted to eat this piece of the cake and permitted to eat that piece of the cake without being permitted to eat both of these pieces. This shows that practical permissions do not agglomerate, and, moreover, that it is not a logical or conceptual truth that permissions agglomerate. What it does not show, however, is that epistemic permissions do not agglomerate, or that they do not agglomerate in the lottery case. For even if it is not a conceptual truth that permissions agglomerate, and not a substantial normative truth that practical permissions agglomerate, it may still be a substantial normative truth that epistemic permissions agglomerate, or that they agglomerate under conditions that the lottery case satisfies. Thus, one cannot conclude from the fact that practical permissions fail to agglomerate that epistemic permissions fail to 
agglomerate as well, or that they fail to agglomerate in the lottery case. This conclusion requires additional assumptions about the norms of belief.

This logical point gives rise to a problem for the permissibility solution, for once we address the relevant normative question directly, it seems actually quite plausible to think that epistemic permissions do indeed agglomerate. An agent has epistemic justification to believe $\mathrm{p}$ just in case she has sufficient evidence for believing p. ${ }^{34}$ Justification agglomeration thus seems to amount to no more than the claim that we are always epistemically permitted to have all those beliefs together for which we have sufficient evidence. Considered as such, this principle seems at least prima facie plausible, and the proponent of the permissibility solution owes us an argument for why it should be rejected.

As it happens, there is indeed a good argument against accepting justification agglomeration without qualification. Suppose that George has sufficient justification for believing p. Next, suppose that George could not be bothered whether $\mathrm{p}$ is the case and therefore does not form a belief about whether $\mathrm{p}$ (he also is quite sure that he will not do so). It seems that in such a case, George has justification for believing p, but George also has justification for believing that he himself does not believe that p. Justification agglomeration yields the result that George has justification for [believing $\mathrm{p}$ and believing that he himself does not believe that p]. However, it looks like having these two beliefs together is indeed not epistemically permissible, and so justification fails to agglomerate in this case. 35

It is not difficult to identify the reason why agglomeration fails in George's case. The problem is that the actual formation of a belief in $\mathrm{p}$ would change his evidence with regard to the proposition that he does not believe that $\mathrm{p}$, thereby undermining the justification he has for believing this proposition. ${ }^{36}$ As the actual formation of one belief undermines the justification for the other, George cannot justifiably hold both of these beliefs at the same time. But surely this is an exceptional case. Typically, the formation of a justified belief does not itself undermine the justification one has for other beliefs, and in such typical cases, agglomeration still seems plausible. Hence, George's case does not cast doubt on the following qualified agglomeration principle:

Justification agglomeration (qualified): If $\mathrm{A}$ has justification for believing $\mathrm{p}$, and $\mathrm{A}$ has justification for believing $\mathrm{q}$, and adopting one of these beliefs does not undermine the justification for the other, then $\mathrm{A}$ has justification for believing $\mathrm{p}$ and believing $\mathrm{q}$.

Since the formation of a belief in one lottery proposition does not undermine (or even affect) the justification we have for believing any other particular lottery proposition, this qualified agglomeration principle applies to the lottery case.

34 Recall that we are concerned with epistemic justification only. By 'sufficient evidence' I mean 'evidence sufficient for providing justification for a belief'. What I say here is compatible with radical views according to which evidence is sufficient only if it guarantees truth.

35 Compare Heylen (2016) and Rosenkranz (20I6, 20I7), who discuss similar cases as counterexamples to the conjunction claim.

36 Could one not have justification for believing that one does not believe $\mathrm{p}$, despite the fact that one believes p? I do not wish to deny that this is possible. But in a case in which one has justification for believing that one lacks a belief in $\mathrm{p}$ despite believing $p$, it is difficult to see what is wrong with saying that one might also have justification for (believing $\mathrm{p}$ and believing that one lacks a belief in p). Hence, such a case does not provide a counterexample to the unqualified version of justification agglomeration. 
Proponents of the permissibility solution might argue that the lottery paradox itself provides reasons to question this principle. That is, they might argue from the probability claim and the wide-scope conjunction claim to denying the qualified agglomeration principle. 37 But as long as there is no independent reason to question this principle, it is unclear why the permissibility solution to the lottery paradox is in any way preferable to the classical solution of Kyburg and others. While the classical solution rejects the conjunction claim in both the standard interpretation and the wide-scope interpretation, the permissibility solution rejects the conjunction claim in the standard interpretation and the qualified agglomeration principle. Both of these views then come at the cost of denying principles with prima facie plausibility, and it is difficult to see how considerations concerning lottery cases themselves could be able to show why the permissibility solution has any advantage over the classical solution, given that the same cases can also be used to motivate the classical solution.

\subsection{Denying justification agglomeration creates a dilemma}

I have argued that the proponent of the permissibility solution owes us an argument for rejecting the plausible assumption that as long as the formation of a justified belief does not undermine the justification for another belief, justification agglomerates. I shall now provide a positive argument for the qualified agglomeration principle. The argument is that denying this principle creates a dilemma. If one denies the qualified agglomeration principle, then one is committed to the following possibility: While forming a number of justified beliefs, a person reaches the point where she is no longer justified in having all these beliefs together, even though each individual belief remains justified. Since she is not justified, she is not permitted to have these beliefs, and since she is not permitted, she is obligated not to have them. So anyone who rejects the qualified agglomeration principle is committed to the existence of epistemic obligations not to have certain sets of beliefs that are such that each belief is individually justified. But how are we to satisfy such an obligation? I shall argue that those who reject the qualified agglomeration principle face a dilemma here. On the first horn of this dilemma, they maintain that it can be fully rational to revise a belief on the basis of the very same evidence on the basis of which one formed the belief in a fully rational way. On the second horn, they accept that there is no rational way to satisfy that epistemic obligation.

Let us consider the lottery case as an example for an alleged agglomeration failure. Proponents of the permissibility solution hold that we have justification for believing each lottery proposition $1_{\mathrm{r}}, \ldots$, and $\mathrm{l}_{\mathrm{n}}$, but we do not have justification for having all of these beliefs together. So if a person forms lottery beliefs, starting from $\mathrm{B}\left(\mathrm{l}_{\mathrm{I}}\right)$, she will at some point acquire a lottery belief $\mathrm{B}\left(1_{\max }\right)$, such that if she adds a further lottery belief $\mathrm{B}\left(\mathrm{l}_{\operatorname{max+1}}\right)$ to her set of lottery beliefs, she is no longer justified in having these beliefs together. $3^{8}$ Now consider the case of Lotta. Lotta acquires individually justified lottery beliefs, and finally arrives at the belief-set $\left\{\mathrm{B}\left(1_{\mathrm{I}}\right), \ldots, \mathrm{B}\left(\mathrm{l}_{\max +\mathrm{I}}\right)\right\}$ that, according to the

37 This is, in effect, the argument against justification agglomeration that Kroedel submits in a later paper (Kroedel 2013 b: 452-3).

38 See also the exchange between Littlejohn (2012, 20I3) and Kroedel (2013a, 20I3b), esp. Kroedel (20I3a: $\$_{3}$ ). Further below, I assume on behalf of Kroedel that max+I is reached exactly when the conjunction of $\mathrm{l}_{\mathrm{r}}$, and ..., and $\mathrm{l}_{\max +\mathrm{I}}$ is too unlikely to be justifiably believed. But this is not an essential 
permissibility solution, she is not justified in having. Since Lotta is not justified, and thus not permitted, to have this set of beliefs, she is obligated not to have it. But how is she going to satisfy this obligation?

In order to satisfy the obligation not to have the belief-set $\left\{\mathrm{B}\left(\mathrm{l}_{\mathrm{I}}\right), \ldots, \mathrm{B}\left(\mathrm{l}_{\max +\mathrm{I}}\right)\right\}$, Lotta needs to revise at least one of her lottery beliefs. But how is she going to do this in a rational way? Plausibly, we can rationally form and revise a belief only on the basis of "object-given" (or "content-related") rather than "state-given" (or "attitude-related") reasons. 39 Object-given reasons for and against beliefs are provided by facts that bear on the truth of the object or the content of the relevant belief, while state-given reasons (if there are any such reasons) are provided by facts concerning the state of having or lacking a belief, for example by considerations concerning the benefits of having or lacking a belief. As already mentioned above, many philosophers maintain that all reasons for doxastic attitudes (or even all reasons for attitudes) are object-given: they hold that pragmatic considerations can provide reasons for wanting to have certain beliefs, or reasons for actions that have causal effects on beliefs, but not reasons for belief. $4^{\circ}$ But even those who insist on the existence of pragmatic reasons for belief often accept that they are irrelevant for the rationality of belief (or, if one thinks that this is different, for the epistemic rationality of belief). ${ }^{4 \mathrm{I}}$ It is a widely accepted point that insofar as processes of belief-formation are epistemically rational, they are guided by evidential considerations (in the broad sense of considerations that bear on the truth of the content of the relevant

assumption of my argument - as far as this argument is concerned, max+I might already be reached when the person acquires the belief that $\mathrm{l}_{2}$.

39 See Parfit (200I: \$2) for the object-given/state-given distinction and Piller (2006) for the content-related/attitude-related distinction. The distinction is related (many would say identical) to the distinction between so-called "reasons of the right kind" and "reasons of the wrong kind"; see Gertken and Kiesewetter (2017) for a recent survey of the literature.

40 See e.g. Gibbard (I990: 37), Kolodny (2005: $\$ 3$ ), Shah (2006), Skorupski (2007), Parfit (20I I: App. A), and Way (20I2).

4I Compare Schroeder (2OI 2: 459), a prominent proponent of the view that pragmatic considerations, such as those provided by Pascal's wager, provide reasons for belief: "being aware of Pascal's reasons - even if you grant the success of his argument - does not make belief in God more rational qua belief. ... So there seems to be a distinctive dimension of rational assessment of beliefs ... that is affected by the epistemic reasons of which the subject is aware but not the pragmatic reasons of which the subject is aware." Foley (1987: 214), another prominent proponent of pragmatism, holds that "all things considered, it can be rational for an individual to believe what is not epistemically rational for him to believe". As Foley grants that the epistemic rationality of belief-formation is not affected by pragmatic reasons for belief, this is fine for the argument of this section, as long as we hold on to the plausible assumption that it must be possible for us to satisfy epistemic obligations in an epistemically rational way. Rinard (2017), yet another proponent of pragmatism, goes so far as to deny that there is any dimension of the rationality of belief that is insensitive to pragmatic considerations: "every belief-state is univocally either rational or not" ( $(\mathrm{I} 28$ ) and "believing against the evidence can be perfectly rational” (I 22). However, her denial seems motivated by a general scepticism about epistemic norms, according to which normative notions such as 'justification', 'permissibility' or 'obligation' are univocally applied to beliefs as well as to actions, and the same standards that apply to the justification, permissibility or obligatoriness of action also apply to the justification, permissibility or obligatoriness of beliefs (cf. Rinard 20I7: I24). This view is fundamentally at odds with Kroedel's approach, which presupposes the existence of epistemic justification, epistemic permissions and (negative) epistemic obligations - it thus cannot be employed on behalf of the permissibility solution. In particular, Rinard's view is incompatible with the probability claim, according to which high evidential probability provides justification for beliefs, which the permissibility solution is designed to preserve. 
belief). ${ }^{42}$ Moreover, what seems plausible for rational process of belief-formation seems equally plausible for processes of belief-revision; these processes, too, must be guided by evidential considerations in order to be epistemically rational.43 Finally, in order for a body of evidential considerations to rationalize the formation or revision of a belief, this body must contain sufficient epistemic reasons for forming or revising this belief: insufficient epistemic reasons for a belief do not rationalize its formation, and insufficient epistemic reasons for revising a belief do not rationalize its revision. 44 Thus, in what follows I will assume that one can rationally revise a belief only on the basis of evidence that provides sufficient object-given reasons for revising this belief.

This assumption poses a problem for the permissibility solution. Let $t_{\text {max }}$ be the point in time when Lotta has acquired the belief set $\left\{\mathrm{B}\left(\mathrm{l}_{\mathrm{I}}\right), \ldots, \mathrm{B}\left(\mathrm{l}_{\max }\right)\right\}$, and $t_{\max +\mathrm{I}}$ the point in time when she has acquired the belief-set $\left\{\mathrm{B}\left(\mathrm{l}_{\mathrm{I}}\right), \ldots, \mathrm{B}\left(\mathrm{l}_{\max +\mathrm{I}}\right)\right\}$. According to the permissibility solution, Lotta is required to give up a lottery belief at $t_{\text {max }+1}$, but not at $t_{\text {max }}$. Her evidence, however, does not change between $t_{\max }$ and $t_{\operatorname{max+I}}$ - all that changes is that Lotta adopts one further lottery belief. 45 But Lotta cannot rationally revise one of her lottery beliefs on the basis of the consideration that she already has too many other lottery beliefs. Considerations concerning the lottery beliefs that Lotta has adopted have nothing to do with the content of any of her lottery beliefs; if such considerations provided reasons for or against lottery beliefs, those reasons would be state-given rather than object-given reasons.

Proponents of the permissibility solution face a dilemma at this point. Either they maintain that Lotta's evidence provides sufficient object-given reasons for revising one particular lottery belief, or they accept that this is not the case. On the first horn, they are committed to the perplexing claim that a body of evidence that indicates that a proposition $\mathrm{p}$ is extremely likely provides sufficient reason for revising a belief in $\mathrm{p}$. This is doubly implausible. For one, because it is in itself implausible to assume that evidence indicating that there is an extremely small chance that a belief is false provides sufficient reasons to

42 See esp. Kelly (2002).

43 Note that this is compatible with the assumption that we can rationally suspend judgment on whether $\mathrm{p}$ on the basis of non-epistemic reasons, e.g. on the basis of the reason that one is tired or distracted. Schroeder (2OI 2: $\$ 2$ ) puts forward similar cases in order to show that there can be state-given reasons against beliefs (and other attitudes). I agree with those who think that such reasons are better understood as reasons against performing certain actions, such as the action of making up one's mind about $\mathrm{p}$, rather than as reasons against the doxastic state of believing p (see e.g. Shah and Silverstein 20I3). Regardless of this question, however, such cases do not cast doubt on my assumption that we can rationally revise a belief that we already have only on the basis of object-given reasons. It seems clear that one cannot rationally revise a belief for the reason that one is distracted, for example. (One may rationally revise a belief in $\mathrm{p}$ on the basis of the consideration that one has formed the belief under epistemically questionable circumstances such as distraction, but only if one thinks that this casts doubt on the assumption that the evidence that one took oneself to have for $p$ was sufficient. Again, this is not an example of a rational belief revision on the basis of reasons that have nothing to do with the truth of $\mathrm{p}$.)

44 This is not to say that it is easy to determine when a body of evidence is sufficient. Here I merely point out that a piece of evidence might support $\mathrm{p}$ without providing sufficient epistemic reasons to believe $\mathrm{p}$ or to revise a belief in $\neg$ p.

45 Note that this is exactly where Lotta's case differs from George's case discussed above. When George forms both the belief that $\mathrm{p}$ and the belief that he does not believe that $\mathrm{p}$, his evidence has changed, and he can give up one of his beliefs on the basis of sufficient object-given reasons. That is why the argument presented here supports only the qualified agglomeration principle. 
revise that belief. For another, because it is implausible to assume that the very same body of evidence can provide sufficient reasons for both forming and revising the same belief, and proponents of the permissibility solution are already committed to saying that Lotta's evidence provides sufficient object-given reasons for each lottery belief. Thus, accepting the first horn of the dilemma commits them to denying the following plausible principle:

Asymmetry principle: If some body of evidence provides a sufficient basis for rationally forming the belief that $\mathrm{p}$, then the same body of evidence does not provide a sufficient basis for rationally revising the belief that $\mathrm{p}$.

On the second horn of the dilemma, proponents of the permissibility solution accept that Lotta lacks sufficient object-given reasons for revising any of her particular lottery beliefs. Given that one can rationally revise a particular belief only on the basis of sufficient object-given reasons for revising this belief, this means that there is no rational way for Lotta to satisfy her epistemic obligation. Accordingly, Lotta can satisfy her obligation only through some irrational process such as wishful thinking or reasoning on the basis of insufficient reasons or some non-rational process such as forgetting. I take it, however, that the absence of an epistemically rational process by which one can satisfy an epistemic obligation undermines the claim that such an obligation exists to begin with. Even though the epistemic 'ought' does not imply voluntary control over doxastic states, ${ }^{46}$ it surely implies some sort of 'can' that goes beyond the possibility of irrational or accidental conformity. In any case, it should be clear that a commitment to epistemic obligations that cannot rationally be satisfied would be a significant cost of the permissibility solution.

The problem generalizes for everyone who denies the qualified agglomeration principle. If justification fails to agglomerate in a case in which the formation of a belief does not undermine the justification for the other, then it is possible that a number of beliefs are individually but not collectively justified. This means that a person who has formed these beliefs is under an epistemic obligation to give up one of her individually justified beliefs. And this creates a dilemma: either we have to assume that it can be fully rational to revise a belief on the same evidence on which it was rational to form that very belief, or we have to accept that there are epistemic obligations that cannot rationally be satisfied. Better, then, to stick with the qualified agglomeration principle.

\section{$3 \cdot 3$ Objections}

In the remainder of this section, I shall discuss two objections to the argument I have given. The first objection is that the first horn of the dilemma can be accepted, because the asymmetry principle is independently questionable. For one, it may be argued that there are borderline cases in which the evidence probabilizes a proposition to a degree such that one can rationally form as well as revise a belief in that proposition on the basis of that evidence. For another, phenomena that are being discussed under the heading pragmatic encroachment seem to show that the standards for knowledge and justification can depend on the pragmatic context, 47 and it seems to follow from this that it can be rational to revise a belief in $\mathrm{p}$ on the basis of the same body of evidence on the basis of

46 Cf. Chuard and Southwood (2009).

47 See e.g. Fantl and McGrath (2002). 
which one has rationally formed it. To give just one example, it may be argued that it can be rational to revise a belief that the time is such-and-such, which one has rationally formed on the basis of testimonial evidence, if one has learned in the meantime that someone's life depends on what time it is now, even though the evidence itself has not changed.

I am not convinced that considerations like these really defeat the asymmetry principle, but this question lies beyond the scope of this paper. I shall instead argue that the dilemma for the permissibility solution remains in place even if we grant both of these points. First of all, let me emphasize that the violation of the asymmetry principle is only one part of the first horn of the dilemma. Even if the asymmetry principle turns out to be false, the point remains that it is independently implausible to assume that a body of evidence that indicates that a proposition is extremely likely provides sufficient reasons for revising this belief.

That proponents of the permissibility solution are committed to this assumption (on the first horn of the dilemma) also shows that it does not help them to accept borderline cases as counterexamples to the asymmetry principle. They have to maintain symmetry of rational belief formation and revision not only in borderline cases but in all cases in which the probability is less than I. What this means is that for all propositions that we have justification to believe, but which are less than absolutely certain (and this will be the vast majority of propositions we have justification to believe), we have sufficient reasons for both forming and revising belief in that proposition; we can continuously go back and forth in forming and revising all such beliefs while remaining fully epistemically rational. This goes far beyond accepting that there may be borderline cases in which the asymmetry principle fails to apply.

Finally, it also does not help the permissibility solution to reject the asymmetry principle on grounds of considerations concerning pragmatic encroachment. This is for the simple reason that the relevant phenomena do not call into question that there is an asymmetry between forming and revising beliefs within one and the same pragmatic context. And we can simply stipulate that no change of pragmatic context occurs in Lotta's case.

The second objection takes issue with my claim that rejecting the first horn of the dilemma (and thus accepting that there is no sufficient object-given reason for revising any particular lottery belief) commits one to the existence of an epistemic obligation that cannot rationally be satisfied. The proponent of this objection holds that in order to rationally satisfy an obligation not to have the combination of beliefs $\left[\mathrm{B}\left(\mathrm{l}_{\mathrm{I}}\right)\right.$, and ..., and $\mathrm{B}\left(\mathrm{l}_{\max +\mathrm{I}}\right)$ ], one does not need sufficient object-given reasons for revising any particular lottery belief, one only needs sufficient object-given reasons for revising $\left[\mathrm{B}\left(\mathrm{l}_{\mathrm{I}}\right)\right.$, or ..., or $\mathrm{B}$ $\left.\left(1_{\max +\mathrm{I}}\right)\right]$. Since the conjunction of $1_{\mathrm{I}} \& \ldots \& \mathrm{l}_{\max +\mathrm{I}}$ is, ex bypothesi, insufficiently likely, Lotta's evidence may plausibly be taken to provide sufficient object-given reasons for revising $\left[\mathrm{B}\left(\mathrm{l}_{\mathrm{I}}\right)\right.$, or $\ldots$, or $\left.\mathrm{B}\left(\mathrm{l}_{\max +\mathrm{I}}\right)\right]$. And so, the objection continues, Lotta can rationally satisfy her obligation even though she lacks sufficient object-given reason for revising any particular lottery belief.

My response is that in order to revise a particular belief in a rational way, we need sufficient object-given reasons to revise this particular belief. Evidence that shows a conjunction of propositions to be insufficiently likely provides a sufficient basis for rationally revising a belief in this conjunction, but it does not by itself provide a sufficient basis for rationally revising a belief in one of the conjuncts. Note that our evidence quite generally suggests that the conjunction of all of our beliefs is unlikely or even inconsistent yet this is no reason on the basis of which we can rationally revise one of our particular beliefs. 
This response may be challenged by way of an analogy to the practical case. You have promised to give me one out of a set of $n$ presents, all of which you like equally well. This is a reason to give me [present ${ }_{\mathrm{I}}$, or ..., or present $\mathrm{n}_{\mathrm{n}}$. Even though it is not a reason to give me one particular present rather than another, you can rationally pick one particular present on the basis of that reason. Why then should it not be rationally possible for us to revise a particular lottery belief on the basis of a reason to revise $\left[\mathrm{B}\left(1_{\mathrm{I}}\right)\right.$, or .., or $\left.\mathrm{B}\left(\mathrm{l}_{\max +\mathrm{I}}\right)\right]$ ?

I take it that the two cases are not intuitively on a par. Intuitively, one can rationally pick one of the presents, but one cannot rationally "pick" one of the beliefs. Rational belief revision is not a matter of picking. This intuitive difference is also reflected in the fact that the most natural explanation of why it is possible for us to rationally decide to give away one particular present does not likewise suggest that it is possible for us to rationally revise one particular lottery belief. The explanation in the practical case is that we have instrumental reasons to take means to actions we have reason to perform and that we can rationally base a decision to take a particular means on such instrumental reasons, provided that these reasons are sufficient and that there is no conclusive reason against taking the particular means. If you have sufficient reason to keep your promise, then you also have sufficient reason to take sufficient means to keeping your promise, and since you have no conclusive reason against giving away present ${ }_{I}$, and doing so is a sufficient means to keeping your promise, you can rationally base a decision to give away present $\mathrm{I}_{\mathrm{I}}$ on this reason..$^{8}$

However, as Jonathan Way has argued convincingly, such principles of instrumental transmission of reasons generally do not apply to object-given reasons for attitudes. 49 For example, if you have sufficient object-given reasons to revise your belief that God exists, and a necessary or sufficient means for you to doing this is revising your belief that life is meaningful, it does not follow that you have any object-given reason to revise that latter belief - and so it does not follow that you can rationally revise it on the basis of the original object-given reason. More generally speaking, rational belief-formation and -revision is not sensitive to instrumental considerations in the way that rational decisionmaking is. Therefore, the analogy to the practical case fails. Even if we were to assume such a thing as an object-given reason to revise $\left[\mathrm{B}\left(\mathrm{l}_{\mathrm{I}}\right)\right.$, or $\ldots$, or $\left.\mathrm{B}\left(\mathrm{l}_{\max +\mathrm{I}}\right)\right]$, it would not follow from this that there is an object-given reason, and thus a rational basis, for revising any of your particular lottery beliefs.

\section{CONCLUSION}

According to the permissibility solution, the lottery paradox can be solved if epistemic justification is identified with epistemic permissibility. Kroedel maintains that such an account of justification would allow us to reject the agglomeration of justified beliefs, and thus to maintain both the probability claim and a version of the conjunction claim, without being committed to the paradoxical conclusion that we have justification for believing that all tickets will lose. I have presented two objections to this solution. First, even if justification amounts to no more than permissibility, there plausibly are obligations to believe what is

48 For discussion of such instrumental reasons, see e.g. Gertken and Kiesewetter (Ms), Kiesewetter (2015), Bedke (2017), Kolodny (Forthcoming).

49 See Way (2010: $\$ 4)$, and esp. Way (2012). 
very likely to be true given certain background conditions, and the lottery paradox can be restated in terms of such obligations. Second, even if there are no obligations to believe lottery propositions, the permissibility solution fails because, apart from exceptional cases in which the formation of a justified belief undermines the justification for another belief, justification agglomerates. Both of these objections show, on independent grounds, that a satisfying solution to the lottery paradox, which accepts the probability claim, needs to reject the conjunction claim in either of the versions distinguished above. $5^{\circ}$

\section{REFERENCES}

Bedke, M. S. 20I7. 'Ends to Means.' Journal of Ethics and Social Philosophy, I2: 6-28.

Chuard, P. and Southwood, N. 2009. 'Epistemic Norms without Voluntary Control.' Nô̂s, 43: 599632.

Eder, A.-M. A. 20I 5. 'No Match Point for the Permissibility Account.' Erkenntnis, 80: 657-73.

Fantl, J. and McGrath, M. 2002. 'Evidence, Pragmatics, and Justification.' Philosophical Review, II I: $67-94$.

Foley, R. 1979. 'Justified Inconsistent Beliefs.' American Philosophical Quarterly, I6: 247-57.

— 1987. The Theory of Epistemic Rationality. Cambridge, MA: Harvard University Press.

- I992. 'The Epistemology of Belief and the Epistemology of Degrees of Belief.' American Philosophical Quarterly, 29: I I I-24.

Gertken, J. and Kiesewetter, B. 20I7. 'The Right and the Wrong Kind of Reasons.' Philosophy Compass, I2: I-I4. https://doi.org/IO.IIII/phc3.I24I2.

— Ms. 'Is There a Liberal Principle of Instrumental Transmission?' Unpublished manuscript, Humboldt University of Berlin, March 2018.

Gibbard, A. 1990. Wise Choices, Apt Feelings. A Theory of Normative Judgment. Oxford: Clarendon Paperbacks (repr. 2002).

Harman, G. 1986. Change in View. Principles of Reasoning. Cambridge, MA: MIT Press.

Heylen, J. 2016. 'Being in a Position to Know and Closure.' Thought: A Journal of Philosophy, 5: 63-7.

Huber, F. 20I4. 'What is the Permissibility Solution a Solution of? A Question for Kroedel.' Logos \& Episteme, 5: 333-42.

Kelly, T. 2002. 'The Rationality of Belief and Some Other Propositional Attitudes.' Philosophical Studies, I Iо: 163-96.

Kiesewetter, B. 20I 5. 'Instrumental Normativity: In Defense of the Transmission Principle.' Ethics, I25: $92 \mathrm{I}-46$.

- 20I7. The Normativity of Rationality. Oxford: Oxford University Press.

Klein, P. I985. 'The Virtues of Inconsistency.' The Monist, 68: 105-35.

Kolodny, N. 2005. 'Why Be Rational?' Mind, i I4: 509-63.

— Forthcoming. 'Instrumental Reasons.' In D. Star (ed.), The Oxford Handbook of Reasons and Normativity. Oxford: Oxford University Press.

Kroedel, T. 20I2. 'The Lottery Paradox, Epistemic Justification and Permissibility.' Analysis, 72: $57-60$

20r3a. 'The Permissibility Solution to the Lottery Paradox - Reply to Littlejohn.' Logos \& Episteme, 4: IO3-II.

Earlier versions of this paper have been presented at the Philosophical Society, Lunds Universitet, and the Practical Philosophy/Ethics colloquium at Humboldt University of Berlin. I would like to thank the participants for helpful discussion, and especially Jan Gertken, Thomas Kroedel, Clayton Littlejohn, Arturs Logins, Thomas Schmidt, an anonymous referee and an anonymous associate editor of this journal for written comments. Work on this paper has been supported by the Deutsche Forschungsgemeinschaft (DFG Project "Principles of the Deliberative Ought"). 
- 20I3b. 'Why Epistemic Permissions Don't Agglomerate - Another Reply to Littlejohn.' Logos

\& Episteme, 4: 45 I-5.

- 2017. 'The Lottery, the Preface, and Conditions on Permissible Belief.' Erkenntnis. https://doi. org/I0.1007/s10670-0I7-99II-5.

Kyburg, H. E. 196r. Probability and the Logic of Rational Belief. Middletown, CT: Wesleyan University Press.

_ I970. 'Conjunctivitis.' In M. Swain (ed.), Induction, Acceptance and Rational Belief, pp. 5582. Dordrecht: D. Reidel.

Littlejohn, C. 20I 2. 'Lotteries, Probabilities, and Permissions.' Logos \& Episteme, 3: 509-I4.

— 2013. 'Don't Know, Don't Believe: Reply to Kroedel.' Logos \& Episteme, 4: 23 I-8.

Makinson, D. C. I965. 'The Paradox of the Preface.' Analysis, 25: 205-7.

Moran, R. I988. 'Making Up Your Mind.' Ratio, I: I35-5I.

Nelkin, D. K. 2000. 'The Lottery Paradox, Knowledge, and Rationality.' Philosophical Review, I09: 373-409.

Nelson, M. T. 20ıо. 'We Have No Positive Epistemic Duties.' Mind, I I9: 83-I02.

Nozick, R. 1993. The Nature of Rationality. Princeton, NJ: Princeton University Press (repr. 1995).

Parfit, D. 200I. 'Rationality and Reasons.' In D. Egonsson, J. Josefsson, B. Petersson and

T. Rønnow-Rasmussen (eds), Exploring Practical Philosophy: From Action to Values, pp. I7-39. Aldershot: Ashgate.

- 20I I. On What Matters. Vol. I. Oxford: Oxford University Press.

Piller, C. 2006. 'Content-Related and Attitude-Related Reasons for Preferences.' Royal Institute of Philosophy Supplements, 8I: I 55-8I.

Rinard, S. 20I 5. 'Against the New Evidentialists.' Philosophical Issues, 25: 208-23.

- 2017. 'No Exception for Belief.' Philosophy and Phenomenological Research, 94: I2 I-43.

Rosenkranz, S. 2016. 'Being in a Position to Know and Closure: Reply to Heylen.' Thought: A Journal of Philosophy, 5: 68-72.

2017. 'The Structure of Justification.' Mind. https://doi.org/I0.1093/mind/fzwo57.

Ryan, S. 1996. 'The Epistemic Virtues of Consistency.' Synthese, I09: I2I-4I.

Schroeder, M. 20I 2. 'The Ubiquity of State-Given Reasons.' Ethics, I22: 457-88.

Shah, N. 2006. 'A New Argument for Evidentialism.' Philosophical Quarterly, 56: 48 I-98. and Silverstein, M. 20I3. 'Reasoning in Stages.' Ethics, I24: IOI-I3.

Skorupski, J. 2007. 'Buck-Passing about Goodness.' In T. Rønnow-Rasmussen, B. Petersson, J. Josefsson and D. Egonsson (eds), Hommage à Wlodek: Philosophical Papers Dedicated to Wlodek Rabinowicz, pp. I-I 5. http://www.fil.lu.se/hommageawlodek/site/papper/SkorupskiJohn.pdf.

- 20I0. The Domain of Reasons. New York, NY: Oxford University Press.

Way, J. 20I0. 'Defending the Wide-Scope Approach to Instrumental Reason.' Philosophical Studies, I 47: $213-33$.

- 2012. 'Transmission and the Wrong Kind of Reason.' Ethics, I22: 489-5 I5.

— 2016. 'Two Arguments for Evidentialism.' Philosophical Quarterly, 66: 805-18.

Way, J. and D. Whiting. 20I6. 'Reasons and Guidance (Or, Surprise Parties and Ice Cream).' Analytic Philosophy, 57: 2I4-35.

Whiting, D. 20I2. 'Does Belief Aim (Only) at the Truth?' Pacific Philosophical Quarterly, 93: 279-300.

BENJAMIN KIESEWETTER is a postdoctoral research fellow at the Humboldt University of Berlin. Before that, he was Visiting Professor at the University of Hamburg, Research Associate at the Australian National University, Canberra, and lecturer at the Humboldt University of Berlin, where he also received his doctorate. He works on reasons and rationality, moral philosophy, metaethics, normative aspects of epistemology and other normative issues in philosophy. His book The Normativity of Rationality was published by Oxford University Press in 2017. His articles have appeared in Analysis, Archiv für Rechts- und Sozialphilosophie, Ethics, Journal of Ethics and Social Philosophy, Journal of Moral Philosophy, Philosophy Compass, and The Philosophical Quarterly. 